\title{
e-Assessment Management System for Comprehensive Assessment of Medical Students Knowledge
}

\author{
Jaroslav Majerník \\ Pavol Jozef Šafárik University in Košice, Faculty of Medicine, Trieda SNP 1, Košice, Slovakia \\ Email: jaroslav.majernik@upjs.sk
}

\begin{abstract}
The evaluation of students' knowledge, skills and performance is one of inseparable parts in education process. Except of various teaching approaches, the history brought also various, more or less effective assessment methods. Nowadays, thanks to the learning management systems, the e-assessment methods become more available and widespread across education institutions. The heterogeneity in usage of various assessment methods at our faculty, as well as involvement of natural subjective factors, forced us to search for the solution that can be applicable and acceptable in all study programs, courses and examinations. Furthermore, the system should be secure, intuitive and available for all teachers and their students. In this paper, we describe main principles and methodology of e-Assessment management system we implemented into the medical education for automatic assessment of students' knowledge and competences at the Faculty of Medicine in Košice, Slovakia.
\end{abstract}

\section{INTRODUCTION}

$\mathrm{P}$ APER based tests and oral examinations have been used as the main forms to evaluate students' knowledge for many years. Traditionally, teachers used the tests in exams to evaluate learners' knowledge obtained during educational process. Some forms of tests were also involved in course requirements to measure concept assimilation presented in lectures or classes [1]. Various clinical performance assessment tools are also used in practice education [2, 3]. However, there is still no general framework of competency assessment in medicine [4].

Advances in information and communication technologies (ICT) reduced the needs of papers and the time the teachers spent by evaluation of individual tests too. Many educational institutions already discovered advantages of modern innovative digital technologies and adopted some type of smart tools to facilitate assessment. Simulations and work-based assessments methods for specific purposes and clinical performance, including medical history taking, physical examination skills, procedural skills, clinical

This work was not supported by any organization judgment etc. have also been used and involved in systems of medical education $[5,6]$. The common electronic assessment tools are integrated either in Learning Management Systems (LMS) that offer complex modules for teaching, learning and assessment within education institution [7], or they are designed as individual or separate systems to fully manage all assessment needs, and are generally known as Assessment Management Systems (AMS). In both cases, assessment practices serve teachers and students as a part of continual teaching and learning.

In general, the e-Assessment management systems can be classified as systems based either on client-server architecture or as web-based services [8]. Nowadays, the majority of administrators prefer to adopt online available AMS, where everything can be organized through networks and without the needs to use any papers. Except of these environmental factors, there is also no need to install any clients on students' devices. Thus, the tests can be accessed anytime and anywhere, no matter which platform is used to manage assessment procedures.

The higher education benefits from the e-assessment as it assists learning and determines the effectiveness of the education system. e-Assessment systems have a great potential to improve or replace traditional paper-based assessment processes. It is because they allow users development and managing of various types of questions and tests; assigning of students to the tests/exams; setting of dates, times and places/rooms for the tests/exams; summarizing of tests results; analysing of questions' quality etc. In addition, a well implemented e-Assessment system and understood by the teachers can save the time needed to organize and evaluate exams. In this point of view, their performance is also positively affected as the marking load is reduced and the results are available immediately after the exam is completed [9]. However, the assessment should have clear purpose and has to match the educational programmes and learning outcomes. Thus, any assessment method must be reproducible to show similar results on different occasions and valid to reflect appropriate 
representation of educational content. Finally, the eAssessment systems are considered comfortable in all assessment related tasks, including measurement and documentation of knowledge, skills, and attitudes of individual learner and/or learning community $[10,11,12]$.

The e-Assessment technology principles should be based on methodology that, except of others, allow examiners to create a bank of questions, to generate different types of tests, to mix questions and/or answers in the tests, to specify exact dates and times when the learners must take the exams and to automatically score and share test results to learners. The capabilities of the e-Assessment systems should be also focused on the ways how the users interact with the systems and how it is adopted to their needs.

Aiming to solve the assessment issues in a complex and comprehensive way, we had to consider various factors and questions. Is there any system that will meet the requirements of our teachers and that can be integrated at institutional level? Do the systems allow specifying assessment plans in relation to the learning outcomes? How to grant the permissions of different groups of users to access the system? These and many other similar questions were solved and discussed during our initiative and resulted in a satisfying solution that was accepted very well by both the teachers as well as by the learners.

\section{MATERIALS AND METHODS}

To find and/or design the AMS that will be well accepted by all of our teachers, we conducted a survey in which we wanted to discover what kind of assessment methods are currently used, what are the preferred forms to evaluate students' knowledge during diagnostic, formative and summative exams, and what are/should be the most preferred features of assessment system.

The survey was realized online using Google forms, and 65 teachers of our faculty participated on it. The findings illustrated wide usage of ICT in everyday praxis, however, the engagement with e-Assessment was only $12,3 \%$, i.e. only 8 of 65 respondents actively utilize some electronic form to evaluate students' knowledge. The responses resulted in the list of features our teachers require from AMS. These features included: possibilities to test large number of students at the same time; place/room independence; protected access and high security of all exams related data; repository of questions and tests; multimedia support in tests; limited access to registered students only; easy to use interface in national language; reporting per examination; and not surprisingly for academic environment, low or no financial expenses.

Except of the above mentioned features, the technicians had to consider numerous technical and administrative related aspects too. Thus, the fully functional e-Assessment system required to solve the tasks related to the safe and reliable server(s), network infrastructure, computer classrooms, and professional administrative staff support.
Comparing the features, technical requirements and supporting documentation of various commercial (AEFIS, beSocratic, Blackboard Learn, Digication AMS, eLumen, LiveText, rGrade, Taskstream) and open-source (openIGOR, Rogō, Unicon, TAO) assessment systems, we decided to test the Rogō system. The Rogō AMS was developed at the University of Nottingham together with partner institutions, now involved in development community. The results of the tests and the functionalities offered in Rogō convinced us to integrate the system into the ICT infrastructure of the faculty including Slovak language pack developed during testing phase. Our decision was supported also by abilities of the system to integrate third party systems, including LDAP authentication and functionalities, which allow a VLE or other LMS to launch and single sign into Rogō.

\section{RESULTS}

The integration of AMS was fully adopted to the faculty infrastructure and requirements. The hierarchic structure reflects the faculty units, study fields, courses with learning objectives, different assessment methods and the users with different roles in the system as it is shown on Figure 1.

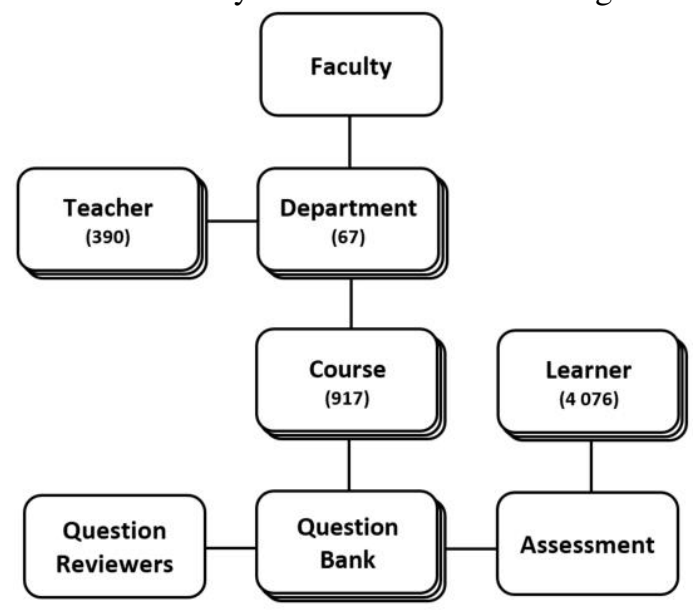

Fig. 1 The structure of e-assessment management system integrated at the Faculty of Medicine in Košice.

All authorised users of the system (teachers, question reviewers and learners) were connected to the accounts of faculty's LMS. Thus, 390 teachers and 4,076 learners were able to use the system without any registration procedures. Similarly, the full list of all courses (917) was imported to the system. Information related to the course registration lists ensured the teachers create questions and examination papers only within their courses and the learners do the exams only in courses they are enrolled in.

Depending on the course management, the Question Banks of particular courses were created by guarantors or by the team of teachers associated with courses. Naturally, the questions can be imported and/or added manually if there is no previously created electronic list of questions. Almost any type of questions is supported that makes the assessment easily adjustable to various types of courses as well as their 
learning objectives. Except of commonly used Multiple Choice Questions (MCQ) the teachers can create questions like Area, Calculation, Dichotomous, Extended Matching, Fill-in-the-Blank, Image Hotspot, Labelling, Likert Scale, Matrix, Multiple Response, Random Question Block, Ranking, Script Concordance Test (SCT), Textbox or TrueFalse as it is defined in the Table 1. The users can combine all these question types in Random Question Blocks if there is a requirement to organize exams with randomly generated questions. Once the questions are stored in the Question Bank then it is possible to export them to external QTI or Rogō files and use them in other systems or in other Rogō instances.

Considering various purposes for which the students are assessed and relations to in-course or end of course teaching activities, there was a need to organise different types of assessment. The most frequent types included summative, formative and diagnostic exams. In summative assessment, the learner performance against the standard knowledge is awarded by grades. Then, the grade can either be a part of in-course assessment, or assessment at the end of a course. Formative assessment is organized during the course, and provides feedback to learners. While the summative assessment is used for certification, the formative assessment helps students improve their learning as the failure rate can be reduced and the performance can be increased. Diagnostic assessment is used to evaluate the level of learning that has been achieved by learners. In general, it can be used at the beginning of the course to determine the level of knowledge, or at the end of lessons to know how the learners understood the topics. However, diagnostic assessment does not provide tools of feedback as it is in formative assessment. Individual types of supported assessment methods are show and described in Figure 2.

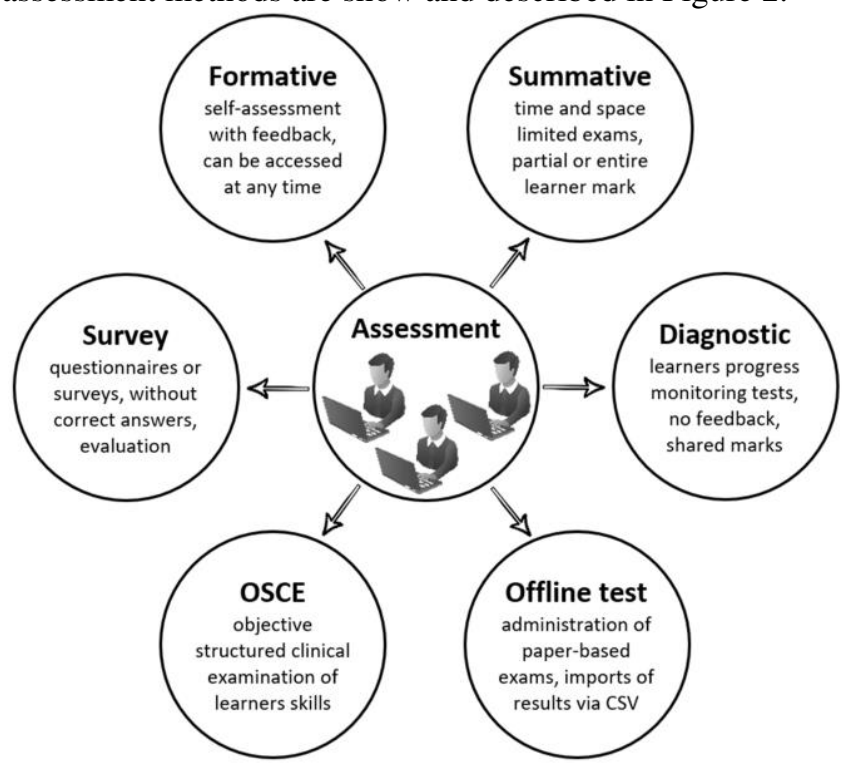

Fig. 2 Assessment methods integrated in e-assessment management system.

The questions for various assessments can be chosen from the same Question Bank of the course or group of courses.

TABLE I.

TYPES OF SUPPORTED QUESTIONS IN E-ASSESSMENT SYSTEM.

\begin{tabular}{|c|c|}
\hline Question type & Purpose and description \\
\hline Area & $\begin{array}{l}\text { To draw a shape around a specified part of an image. The most commonly used formats including JPG, GIF and } \\
\text { PNG are supported. }\end{array}$ \\
\hline Calculation & $\begin{array}{l}\text { To use one or more variables (random values) specified in the task by the teacher and to define formula for } \\
\text { verification of calculated value given by the learner in the answer field. }\end{array}$ \\
\hline Dichotomous & $\begin{array}{l}\text { To present a lead-in question together with a number of stems displayed below. The learner must select either True } \\
\text { or False for each stem. }\end{array}$ \\
\hline Extended Matching & $\begin{array}{l}\text { To present multiple scenarios based around a common theme. Each question has the same list of options from } \\
\text { which the learner is asked to choose the answer. }\end{array}$ \\
\hline Fill-in-the-Blank & $\begin{array}{l}\text { An alternative to open ended question. Used to allow learners fill-in the blank textboxes or to select answer from } \\
\text { dropdown lists. }\end{array}$ \\
\hline Image Hotspot & $\begin{array}{l}\text { To identify parts of the graphic, e.g. anatomical structures, body regions etc. One question may cover up to } 10 \\
\text { different items to be identified by the learner. }\end{array}$ \\
\hline Labelling & $\begin{array}{l}\text { To place labels (one label can only be used once), using drag and drop method, to the spaces shown over the } \\
\text { graphic. }\end{array}$ \\
\hline Likert Scale & To list the answers with the support of both Likert Scales and Semantic Differential questions. \\
\hline Matrix & $\begin{array}{l}\text { To reduce test space via better visual appearance. The questions are presented in rows with possible answers as } \\
\text { columns. Radio buttons are used as only one answer per row can be selected. }\end{array}$ \\
\hline Multiple Choice & $\begin{array}{l}\text { To choose correct answer from up to } 20 \text { options. Radio buttons are used in the interface so that only one option can } \\
\text { be selected. }\end{array}$ \\
\hline Multiple Response & To identify various number of correct options. Each option can be selected or unselected. \\
\hline Ranking & To see if the learner can put various options in the correct order. \\
\hline Script Concordance Test & To assess reasoning skills in clinical situations, specifically those with uncertain scenarios. \\
\hline Textbox & To collect written answers, e.g. open-ended textual questions used for surveys. \\
\hline TrueFalse & To confirm statement that is displayed with an option that is either True or False. \\
\hline
\end{tabular}


The system holds large amount of highly important data which must be kept safe at all times. Therefore, the users' data, question banks, exam tests, results as well as all the information stored in AMS are secured using several protection levels. From the security point of view, it is very important that the summative exams are not available anytime and anywhere. The students should not find the tests before the exam dates and the results must be delivered to them securely. On the other hand, the security issues are not necessary to be so strict in formative assessments.

Summative assessments can only be taken by learners assigned to the course during the time allocated to the exam in specific allocated room or place. Thus, the summative tests are not accessible to the students anywhere and at any other time. To increase security, the tests and all questions are locked and cannot be amended to ensure that the questions in the bank accurately match the results of the exam. The protection levels used in summative exams are shown in Figure 3.

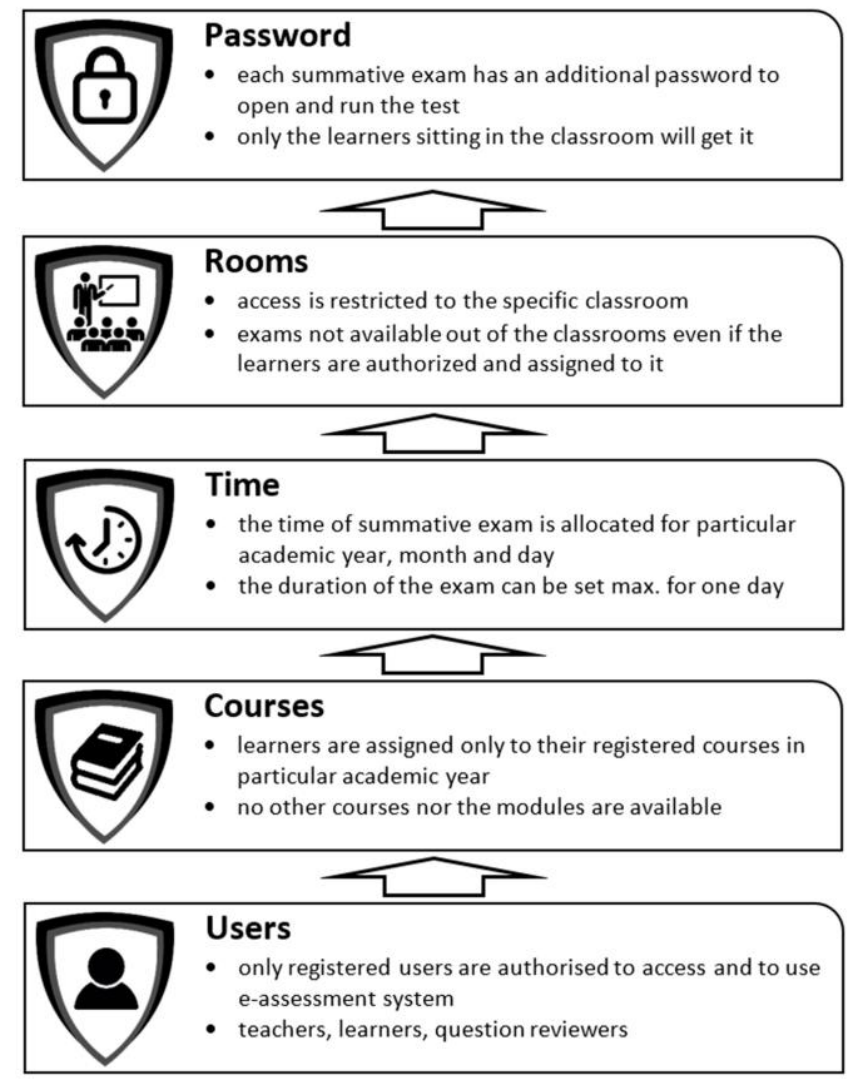

Fig. 3 Security levels applied in summative assessment.

Despite of combination of various security levels there were still some doubts of teachers related to the personal authentication of learners to be sure that the learner completing the assessment is learner that confirmed its identity. Regarding the importance of particular type of assessment, the summative types have to be delivered under invigilated conditions using secure systems. Other assessment forms, where no grading of the results is required, need not to be additionally secured. Thus, for example the formative assessments can be opened to be completed anytime, anywhere and even using learners own devices connected either to the faculty or commercial network. On the other hand, all summative exams at the faculty are organized using advanced mechanisms for personal as well as for equipment identification. Figure 4 shows main concept of additional summative assessment security mechanism we implemented to ensure the summative exams are performed personally by the learners.

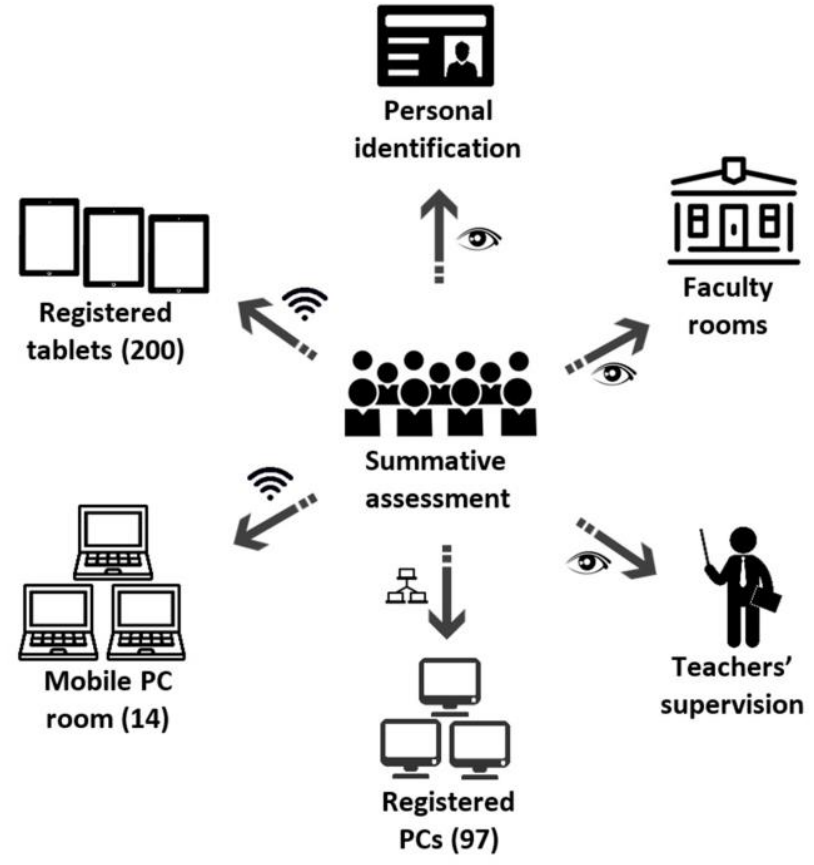

Fig. 4 Additional security mechanisms incorporated into the summative assessments.

All summative exams are organized only in designated faculty computer classrooms and/or lecture halls depending on the size of tested group. The learners are identified by the teacher(s) before they will enter the examination room. Learners' personal identification cards can be used in all lecture halls to register attendance. One or more teachers supervise the summative examination and offer the support to the learners if they have some technical problems during exam. Six computer classrooms with 97 PCs all together are used to test smaller groups of learners. All computers are protected and the internet connection is blocked. The eAssessment is the only available service during the exams. If the test is restricted to the particular room, then it is not possible to see and open it in another room even if the learner is authorized to perform it. Small groups of learners can be also tested everywhere at the faculty using mobile computer classroom where the connection to the eAssessment system is realized through protected and hidden $\mathrm{WiFi}$ network that is a part of that mobile classroom. However, the biggest challenge was to assess the mass of all learners in particular study field. Therefore, we built a network of secured wireless hotspots across main lecture halls (12 all together). This network has also restricted 
access limited to the e-assessment system. In these lecture halls, the learners are doing the summative exams using tablets (200 learners can do the exam in one lecture hall). The tablets are set to access the exams only and everything is preloaded. So the learners are only asked to login to the system, to enter the exam's password that is announced by the teacher once the exam will start and to do the exam.

The AMS is also prepared to solve some problems in the case of unexpected events. The most frequently mentioned doubts of the teachers during their first exams related to the network failures or problems with computer hardware. The system registers each activity of the learners during exam. Therefore, if there is a network failure or computer related problem and AMS cannot be reached, then the assignment can be extended until the problem is solved. Then, the learner can be logged into the system again and continues to solve the exam with all previously marked answers. However, during almost two years' experience we noticed only one problem related to $\mathrm{WiFi}$ failure and no problems with PCs. So, the likelihood of such failures is very low.

The system was successfully implemented into the faculty infrastructure and the number of involved teachers is continuously growing. During the period of almost two academic years, the teachers generated almost 1,200 summative exams with more than 8,500 tests and more than 46,000 questions in their question banks.

\section{CONCLUSION}

Implementation of AMS into the education at our faculty minimized the subjective assessment factors and saved the time of our teachers. Of course, many of them disagreed when they started to use it. Initially, they were loaded by the same tasks and problems as it was in paper-based forms. It was because they had to spend time by preparing questions and organizing of all assessment issues. Teachers mind was changed once they understood this is a long-term investment, in which the lifecycle of e-assessment material will save considerable development and supporting workload. Integration and adaptation of AMS brought also many other advantages, as reported by the teachers. These include possibilities to generate both the summative and formative exams with various types of questions; to follow progress in individual learners through stored results; to obtain course feedback or to identify problematic parts in taught topics via analysis of collected answers.

In the next stage of our work we plan to increase the awareness of formative assessment benefits among our teachers to be utilized more frequently in their curricula. The great potential of formative assessment is in instant feedback and continuous monitoring of learners' progress through which they can identify areas of their weakness and are motivated to study for better understanding of particular topics before final summative exams will take place.

The teachers have variety of reasons to use assessment tools, including to pass or fail students, to grade students, to select best ones for future courses, to prove what students have learnt, to reveal strengths and weaknesses of both students and courses, and many others. When implementing an AMS, it is necessary to clarify requirements and needs of particular educational institutions and staff working at these institutions. Only the well fitted system can be accepted across whole institution, can satisfy the need of users and may have positive effect on overall performance.

\section{ACKNOWLEDGMENT}

Results presented in this work were obtained with the support of the national agency's grant KEGA 017UPJS$4 / 2016$ "Visualization of education in human anatomy using video records of dissections and multimedia teaching materials".

\section{REFERENCES}

[1] Y. Lee, "Assessment Management System based on IMS QTI 2.1", International Journal of Software Engineering and Its Applications, Volume 8, Number 1, 2014, pp. 159-166, http://dx.doi.org/ 10.14257/ijseia.2014.8.1.14.

[2] A. O'Connor, O. McGarr, P. Cantillon, A. McCurtin, A. Clifford, "Clinical performance assessment tools in physiotherapy practice education: a systematic review", Physiotherapy 104, 2018, p. 46-53, https://doi.org/10.1016/j.physio.2017.01.005.

[3] J. Kubicek, T. Rehacek, M. Penhaker, M., I. Bryjova, "Software simulation of CT reconstructions and artifacts", Lecture Notes of the Institute for Computer Sciences, Social-Informatics and Telecommunications Engineering, LNICST, Volume 165, 2016, Pages 428-437, http://dx.doi.org/10.1007/978-3-319-29236-6_41.

[4] E. Sureda-Demeulemeester, C. Ramis-Palmer, A. Sesé-Abad, "The assessment of medical competencies", Rev Clin Esp. 2017, 217(9), pp. 534-542, http://dx.doi.org/10.1016/j.rceng.2017.05.004.

[5] J.J. Norcini, D.W. McKinley, "Assessment methods in medical education", Teaching and Teacher Education, 23, 2007, pp. 239-250, http://dx.doi.org/ 10.1016/j.tate.2006.12.021.

[6] S.C. Daly et al., "A Subjective Assessment of Medical Student Perceptions on Animal Models in Medical Education", Journal of Surgical Education, Volume 71, Number 1, 2014, pp. 61-64, http://dx.doi.org/10.1016/j.jsurg.2013.06.017.

[7] J.G. Moura, L.O. Brandão, A.A.F. Brandão, "A web-based learning management system with automatic assessment resources", Frontiers In Education Conference-Global Engineering: Knowledge Without Borders, Opportunities Without Passports, 2007. FIE'07. 37th Annual. IEEE, 2007.

[8] O.F. Bukie, "Understanding Technologies for E-Assessment: A Systematic Review Approach", Journal of Emerging Trends in Computing and Information Sciences, Vol. 5, No. 12, 2014, pp. 936 947.

[9] Y. Lee, "Assessment Management System based on IMS QTI 2.1", International Journal of Software Engineering and Its Applications Vol.8, No.1 (2014), pp.159-166, http://dx.doi.org/10.14257/ijseia. 2014.8.1.14.

[10] M. Amelung, K. Krieger, and D. Rosner, "E-Assessment as a Service", Ieee Transactions on Learning Technologies, Vol. 4, No. 2, 2011, pp. 162 - 174, http://dx.doi.org/10.1109/TLT.2010.24.

[11] J. Živčák, R. Hudák, T. Tóth, "Rat skin wounds tensile strength measurements in the process of healing", IEEE 10th Jubilee International Symposium on Applied Machine Intelligence and Informatics, SAMI 2012 - Proceedings, 6208996, pp. 389-392.

[12] D. Schwarz, P. Štourač, M. Komenda, H. Harazim, M. Kosinová, J. Gregor, R. Hůlek, O. Smékalová, I. Křikava, R. Štoudek, L. Dušek, "Interactive algorithms for teaching and learning acute medicine in the Network of Medical Faculties MEFANET, Journal of Medical Internet Research, 2013, 15 (7), art. no. e135. http://dx.doi.org/10. 2196/jmir.2590. 